\title{
Development of a knowledge sharing framework for improving the testing processes in global product development
}

\begin{abstract}
As identified by Griffin (1997) and Kahn (2012), manufacturing organisations typically improve their market position by accelerating their Product Development (PD) cycles. One method for achieving this is to reduce the time taken to design, test and validate new products, so that they can reach the end customer before competition. This paper adds to existing research on PD testing procedures by reporting on an exploratory investigation carried out in a UK-based manufacturing plant. Exploring the organisational and managerial factors that contribute to the time spent on testing of new products during development. The investigation consisted of three sections, viz. observations and process modelling, utilisation metrics and a questionnaire-based investigation, from which a proposed framework to improve and reduce the PD time cycle is presented. This project's main focus is the improvement of the utilisation of product testing facilities and the links to its main internal stakeholders - PD engineers.
\end{abstract}

Keywords: Product Development, Product Testing, Information and Knowledge Management, Knowledge Sharing, Communication and Collaboration.

\section{Introduction}

A key aspect of product development is to challenge current thinking and develop new ideas to innovate and improve existing manufacturing technologies in order for products to be manufactured in less time at less cost and improved quality, fulfilling customer needs in the shortest time possible (Kahn, 2012). A review of published literature relating to New Product Development (NPD) and time to market reported that a substantial number of publications emphasised the importance of shortening product life cycles and bringing products to market first in order to establish competitive advantage and gain greater market share before competitors enter the market (Cooper et al., 2001, Afonso et al., 2008, Minderhoud and Fraser, 2005). However, the literature also reported that research has mainly focused on product design, manufacturing and other repetitive processes. This indicated that there is a gap for product testing which is of high value and, although the testing process is repetitive, the nature of the testing is typically one-offs. Consequently, this is usually overlooked by academics. However, product testing and design validation is a major time 
consumer within the NPD cycle and streamlining this process will reduce time to market while still keeping quality and reliability right at the first time (Lu et al., 2000).

Existing literature reports that communication, information and knowledge sharing between internal and external stakeholders are critical factors in successful NPD, since miscommunication and misunderstandings during a project can easily result in costly and timely delays for the NPD cycle (Alavi and Leidner, 2001, Becker and Zirpoli, 2003, Mohannak, 2013). To address these issues, this research focuses on developing a new methodology to improve communication and knowledge capture / sharing for the PD testing team. The aim of this research is to investigate how NPD testing facility performance can be improved, by identifying issues and solutions that can be implemented in an industrial setting affecting multiple sites in different geographical locations. These solutions should result in a positive effect on the time to market of the NPD cycle.

This paper is structured as follows: Section 2 provides a review of current literature relating to the investigation carried out, examining various topics, including NPD, product testing and validation in NPD, communication and teamwork collaboration, and knowledge sharing. The literature survey is followed by a brief overview in Section 3 of the collaborating company where the investigation has been conducted. In Section 4, details of the investigation are provided and discussed, from which the proposed framework and the conclusions of this research are presented.

\section{Literature Survey}

\subsection{Product Testing and Validation Processes in NPD}

Testing is an essential part of PD and is one of the major time consuming processes within the PD life cycle (Dahan and Mendelson, 2001). Testing for NPD can be divided into three main sections: Design Validation, Product Validation and Product tweaking. During design validation, a new design idea is tested as a verification of that idea so that it can be implemented into the product design. During product validation, the product design is almost concluded and the purpose of the testing is to validate the design as a whole and to check that the product fulfils the product specifications. Product tweaking improves product performance by adjusting product parameters / settings. The verification, validation and tweaking of PD designs are critical, as they not only demonstrate product performance but also directly influence product performance improvement, functionality and customer perception. 
Maropoulos and Ceglarek (2010) analysed the difference between verification and validation in the context of engineering design. In their work they looked at the PD process from conceptualisation right up to product certification, from which they highlighted the complexity involved in the product lifecycle and how important Computer-Aided Engineering (CAE) tools are in accelerating design validation, making it a high industrial priority as a time saving, cost cutting and resource usage saving for NPD. Their research was predominantly focused on product design and the use of Computer Aided Design (CAD) tools to keep the design cycle within the design office. However, CAD and CAE tools do have a place in a testing facility and these tools can be used as a simulation tool enabling specific installation planning or test jig design being prepared beforehand; therefore, contributing to time saving within the NPD cycle.

Kleyner and Sandborn (2008) developed a methodology to minimise the life cycle costs of a product by developing an optimal product validation plan. Their framework considered the costs involved in future repairs and warranties in relation to the costs involved in development testing. In other words, if the predicted repair costs are low, minimal validation testing is required and, therefore, shortening the testing plan would result in a time and resource saving. The developed model was validated by an automotive electronics application. The results of their work provided application-specific optimal product validation plans and evaluation of the efficiency of a product validation program from a life cycle cost point of view. Maravelias and Grossmann (2004) also looked at optimising PD testing plans for pharmaceutical companies. They developed an algorithm which predicted the optimal testing schedule with the real life constraints - that of availability of resources and the actual cost, such as the cost implications involved in testing is accelerated due to consideration of the resources availability.

$\mathrm{Lu}$ et al. (2000) and Jürgens (2013) argue that to shorten time to market, the PD process needs to change its way of working from the classical 'wait and react' to 'anticipate and prevent' as early as possible in the development process. In order to do so, they examined the concept of accelerated stress testing for NPD as shown below in Figure 1.

Accelerated stress testing is a classical solution for the implementation of tests where product failures need to be activated faster and cheaper in a well-controlled environment at an early stage of PD. Their research demonstrated that these accelerated test strategies are mainly based on generic lists of failure mechanisms and have only very limited relation with the actual failure rate curve of products. Currently 
available accelerated stress testing strategies do not take into account the four-phase roller coaster failure rate curve, but only the constant failure rate. Systematic strategies for testing all the phases of the failure rate curve can be derived based on maturity index on reliability analysis, the knowledge of the four-phased roller coaster curve and the stresssusceptibility concept (Lu et al., 2000).

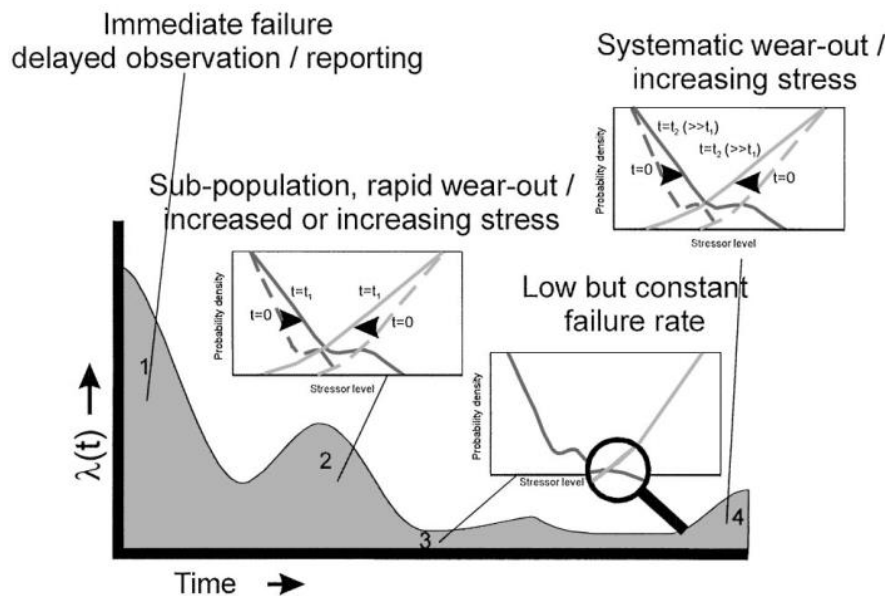

Figure 1. Four-phase roller coaster failure rate (Lu et al., 2000).

\subsection{Communication in NPD}

Without proper communication, any NPD team would not be able to function properly which forms part of the social aspect that NPD collaboration is based upon (Akdevelioglu, 2015). It may be argued that social problems are contributed from relationships between people and that these are an essential and central part of human nature, but social problems are generally a consequence of breakdowns in communication, interactions and cooperation between different races, classes or departments (Argyle, 1969, Daim et al., 2012). The failure to do so can create potential threats, conflict and stress which disrupts the flow of the project due to the failure to manage the relationship between the different parties within the team (Akdevelioglu, 2015).

Communication is the glue that brings people together and is a two-way channel which involves transmitting and receiving sensory data (Fuchs et al., 2010, Gentry and Kuhnert, 2007). The language used aids people to convey information, but verbal communication is not the only communication means an individual can use to convey his/her message. Non-verbal communication can provide an important input to the receiver 
of information. The person conveying the message may reveal clues as to some unspoken intention or feeling through their physical behaviour (Phipps, 2012). These behaviours can include body posture, gestures, facial expressions and eye movements. Body language is typically a subconscious behaviour and is, therefore, considered distinct from sign language, which is a fully conscious and intentional act of communication; because this type of communication is subconscious and therefore hard to fake, it can easily be used to determine if someone is lying. By improving face to face communication, a person's body language can be used to improve trust in the social interactions employees have with their colleges.

\subsection{Team Working and Collaboration}

Teamwork can be defined as the ability to work together toward a common vision, with the ability to direct individual accomplishments toward organizational objectives (Mercer and Myers, 2013). If team members do not work in sync, the group is just a team of people forced to work together who are on a possible course towards failure. Research (Jones and George, 1998) has shown that teams work better together when the members of a team are close friends - this enables individuals to communicate better and think more positively towards the project at hand. The effectiveness of any team can be triggered by various issues that can have either negative or positive effects towards team members. The most common issue affecting teamwork is human emotion (Nair et al., 2005, Farh et al., 2012); as people have their ups and downs this affects their behaviour and preferences which can disturb the entire team. Ultimately, the key point for successful teamwork is to have the team working towards common expectations; this can be described as a shared mental model. However, agreeableness is not always conducive to progress and conflict forces people to challenge conventional thought (Hoegl, 2005, Crawford and Lepine, 2013). 


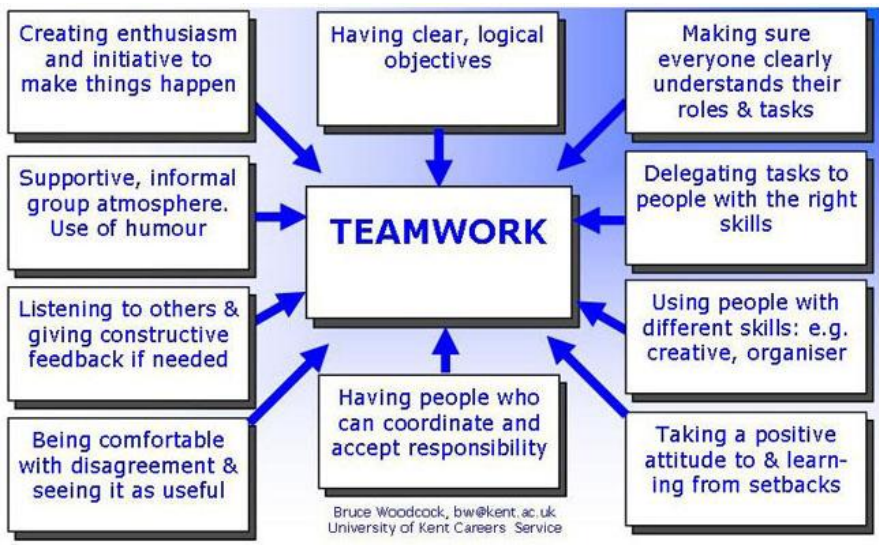

Figure 2. Teamwork improvement points (Woodcock, 2014).

Successful teamwork needs to promote a behaviour that encourages team members to interact with one another and share information and knowledge for the good of the team and company. One way to improve teamwork is by utilising training sessions for teams, which promote teamwork and enhance team performance. Studies have concluded that team training is "useful for improving cognitive outcomes, affective outcomes, teamwork processes, and performance outcomes" (Salas et al., 2008). Apart from learning a specific subject, the participants also get to know other people within the company and, therefore, create friendships; secondly team training usually encourages open discussions, enabling people to share their own knowledge and experiences. In any team, teamwork is a challenging task in itself, which requires strong communication skills, diplomacy, negotiation and patience. Figure 2 shows some critical points that help improve teamwork (Woodcock 2014).

\subsection{Knowledge Sharing}

Organisational competitiveness is rooted in the mobility of knowledge that is realized through knowledge sharing and transfer, providing individuals, teams and organisations with the opportunity to improve the work performance as well as create new ideas and innovations (Cummings, 2004). In any company, knowledge is shared on a daily basis, whether the knowledge process is managed or not. This occurs each time an individual asks a colleague for help, making it an unofficial knowledge transfer. These knowledge transfers are part of organisational life, however, they are often local and fragmented. In general, problems are discussed with local colleagues due to convenience, but this does not guarantee that the best person has been consulted, on the subject (Davenport and Prusak, 2000, Bhatt, 2001). Spontaneous and unstructured knowledge sharing is an 
important aspect of everyday life in a company, but a structured knowledge management system enables, encourages and promotes the spontaneous creation of this knowledge.

Knowledge can be classified into two categories: explicit knowledge, which can be expressed formally and tacit knowledge, which is based on skills and understanding making it very difficult to share and exchange by formal and systematic methods (Miller, 1998); this makes tacit knowledge hard to transfer from one individual to another other, unless they spend a considerable amount of time together and the expert of the two is willing to share his/her knowledge; This mentoring experience within a company is not always possible due to costs involved.

A definition of knowledge sharing provided by (Yang, 2004) explained that it is the dissemination of information and knowledge within an organization. Hislop (2002) proposed that knowledge can be transferred by means of explicit knowledge which has been translated by the sender for the receiver. The receiver then needs to interpret the information into knowledge, as is illustrated in Figure 3.

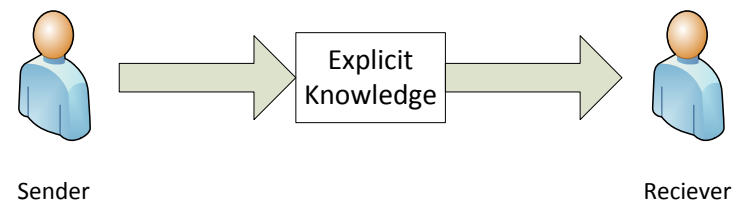

Figure 3. Knowledge Transfer Model

Nonaka and Takeuchi (1995) argued that tacit knowledge is difficult to capture and share due to the personal understanding of the subject matter. They stated that only tacit knowledge that can be transformed into explicit knowledge can be successfully shared. Hislop (2002) suggested that tacit knowledge can be shared through 'direct communication among individuals' and provides three examples from the literature as to how this may be achieved. These were 1) stories, 2) observing others and 3) learning by doing within a community. Therefore, one can argue that if you can capture a person's knowledge and experiences using one of these three techniques, tacit knowledge can be captured and documented in order to be shared with others.

\section{Industrial investigation}

\subsection{Background of the collaborating company}

The company involved in this research forms part of a larger corporation of business units that design, manufacture, distribute and service a vast 
engineering product range. Company employees are dispersed around the globe, serving customers in approximately 190 countries.

The company is organised into four distinct business units; this industrial investigation is centred on one of these business units, which designs, develops and manufactures high value, low volume engineering products for civilian and military applications where high quality and reliability are critical for the product operational lifetime.

\subsection{Case Study Design}

Product testing and design validation in PD is both complex and a time critical task, which has its own challenges due to the uniqueness of each project being developed. The outcome of this research is aimed to improve the testing development time, consumed at a PD testing facility by identifying processes and procedures which affect the everyday testing routine and ultimately the PD cycle. A qualitative case study approach was adopted through an exploratory industrial investigation at a NPD testing facility. The qualitative approach provides a much more subjective view point, due to the open-ended nature of the investigation (Bryman, 2006). The investigation was divided in to three sections: 1) Physical observations, 2) Introduction of utilisation metrics to monitor facilities usage and 3) A semi - structured questionnaire, completed by forty-five employees, selection criteria varying by age and education level in order to obtain a balanced user experience, representing the complete workforce, which was carried out by email, face to face interviews and telephone interviews. The questionnaire consisted of 24 questions divided into three categories, communication, processes and data \& knowledge. The questionnaire was initially sent out by email, resulting in a $60 \%$ response rate, a $100 \%$ response rate was achieved by setting up face to face interviews and telephone interviews.

The observations and process modelling allowed for a better understanding of the company's current status. The second mode of investigation, that of utilisation metrics, highlighted problem areas and bottlenecks in the PD testing cycle. The third mode of investigation, an investigative questionnaire, explored the opinions and know-how of the people at the PD testing facilities and their collaborators in other departments, highlighting real-world issues faced by PD teams.

\subsection{Industrial Investigation}

The process flow of the PD testing and product validation used by the industrial collaborator is presented in Figure 4; this shows the complexity that PD testing entails. The diagram shows the current (AS-IS state) 
processes flow, which every new product goes through for its PD validation.

The starting point of the process flow, shown in Figure 4, begins with the issue of the Design Verification Plan \& Report (DVP\&R) document to the testing facility which describes the product under test and which design validation tests are to be performed. The completion of the process flow ends with the completion and approval of the DVP\&R document reporting back the test results of the validation testing.

From this diagram, it can be seen that much communication and information / knowledge needs to be transferred each time in order for the testing process to be successful and 'on time'. Unfortunately, most of this communication is performed manually, either through verbal or written communication. Occasionally, stakeholders miss out on important communications and end up working with out of date information resulting in timely and costly mistakes.

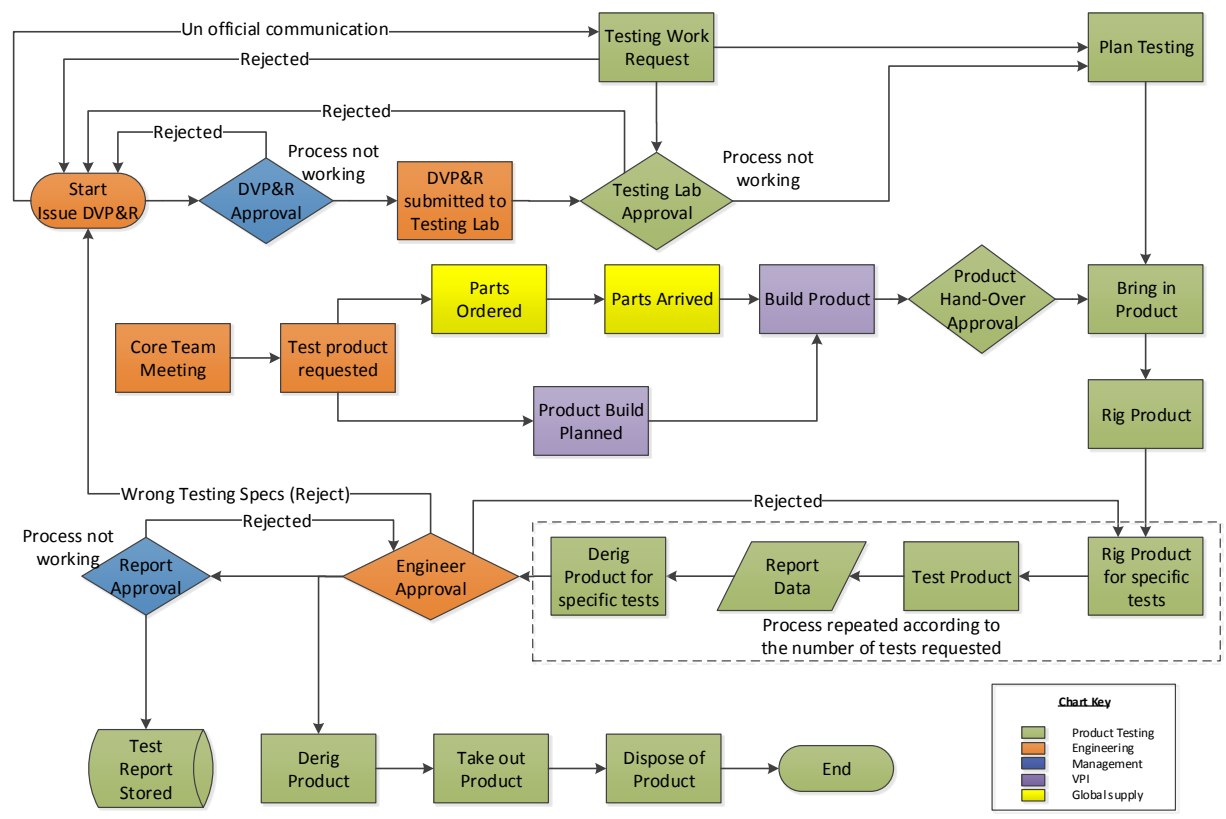

Figure 4. Product Development Testing Process Flow

Highly experienced employees know where to find the correct information and how to interpret the data available, but this is becoming harder over time due to the increased demand for global experts in PD projects in order for a company to remain competitive. For less experienced employees, the risk of making wrong decisions, leading to waste and mistakes, has become a serious issue to resolve for the future. 
Current employees at the collaborating company are motivated and often persevere to ensure the company delivers products of the right quality and standards to the customer, but this can lead to long and sometimes stressful working days which sometimes strain the inter department relationships.

\subsection{Industrial Opinions on Issues Related to Communications}

The first question queried the communication methods used with on and off-site personnel. This resulted in a consensus that most of the staff across a variety of levels use the same communication tools, that of email, web-based chat, telephone calls and face to face meetings.

When asked how collaboration between staff could be improved, it was commonly agreed that more work needs to be done by the company to improve communication amongst project teams and make it more focused to the individual area of interest. Also highlighted was the importance of face-time communication; traditional text-based communication made people feel impersonal and less part of the project team. Additionally, in regards to information sharing, staff commented that they felt they are kept in the dark and vital information for their job function was not readily available, as can be seen in the following quote:

"I have to collaborate in order to complete my work function, I find it vital to talk to people involved ideally face to face on a daily bases in order to make sure that people understand what I need from them and to get the job done."

Another issue that people felt strongly about was the need to remove departmental barriers, the "US \& THEM" mentality. This mentality is not company policy, but the fact that employees perceive this as a problem that can hinder teamwork and ultimately the achievement of the project goals.

"Some people's mentality is the problem, with a "Them \& Us" attitude instead of trying to work as a team; it's easier to just blame others. A day working with staff from other departments might break down these barriers."

When asked how communication can be improved, a clear consensus was evident from the response. Employees commented that better tools are required to keep all relevant parties informed on project status; once again, more face-time was mentioned and also the need to feel more involved. Another issue was to have a more defined framework for structured communication between milestones. It is felt that people will not report updates unless they are obligated to, due to the information gate; this results in relaying information too late in the game whereas if 
done earlier, it would have been more beneficial. There were also complaints about the rigidity of the workflow process and that people use it to their advantage to hide behind it, as is witnessed in the following quote:

"Break down the silos that still exist between departments, this includes Engineering. Need more transparency, still a lot of them and us mentality at all levels of the organisation."

When asked about what shape and form a new communication framework should be in, the issue of face-time was highlighted once again. The importance of putting a face to the message seems to be very important. This is only natural because text based communication can easily deceive recipients. Being that this is internal communication, it is important that it is transparent and honest and the ability to see a person's face or their body language / non-verbal communication can help you deduct if one is being truthful or not.

"Anything that promotes more face to face discussions and more regular reporting."

Participants also mentioned the importance of having a forumbased system which is able to capture dialogue during the PD cycle and which is time stamped and reaches all of the relevant people. This could be in the form of a PD diary, which a person new to the project or who has even worked on it but needs to refresh their memory can go to, to easily understand the development process and the rationale behind decisions that were taken at the time.

"Written communication is authenticated with time stamps, face to face bridge short comings. Important for engineers is to educate themselves about what is involved to conduct specific tests and that they should from time to time participate at the testing facility to get a better understanding."

In summary this portion of the study highlighted several issues relating to inter-departmental communications and distrust in them and provided the need to develop the proposed framework detailed the next Section.

\subsection{Industrial Opinions on Issues related to Processes}

When asked how business processes could be improved, several issues were mentioned, such as better and smarter test planning to having a proactive rather than a reactive approach. Complaints on the documentation structure were also pointed out to improve accessibility of information. The testing facility staff would welcome more time to work on product performance and avoid rushing tests to meet delivery 
deadlines; obviously, this would be a nice commodity, but unfortunately in today's market, time always appears against PD project. Customers want their products yesterday, subsequently at present, there is no method for this to be improved. Another issue highlighted by the testing facility staff was to change the mentality of not implementing lessons learned which are encountered during product testing. This issue was also noticed by the researcher and it is a lost opportunity that some lessons learned are not filtering through to improve the product being tested for new future products.

"More testing bays to improve utilization, apart from having more test cells the need for preparations areas would greatly help the testing facility team to improve their facility utilization. Each test cell should have a prep area where the product can be pull on to for product servicing or maintenance."

With regard to planning within the testing facility, the testing staff complained that little buffer time is allocated especially when the test requirements are vague. This statement is very troubling because testing requirements should be set up from the offset by the engineering team. In the current economic climate, companies cannot rely on 'vague' specifications and expect other people downstream within the PD cycle to make good of the vagueness implicit from the start. Another issue pointed out by the engineering team was the lack of testing ownership from the testing facility side. This has also been noticed and highlighted by the researcher, but more ownership needs to be provided from both sides during the observations, it was noted that some tests could have been avoided if either the engineer witnessing the test or the testing technician questioned the test or data. It is imperative to get product testing right the first time round to keep PD testing costs under control. Another interesting point highlighted was the need to improve time keeping during PD testing, in order to improve planning estimates in the future. This can easily be addressed by means of a proper utilization $\&$ a time sheet database which could result in dividends in time planning.

"I think the intentions are good and training and guidance are also good. However, there is often little buffer time allowed and things often go awry once a vague requirement cannot be met."

With regard to planning from engineering and management, the majority of the testing facility personnel agreed that better planning from the management side is required and realistic deadlines should be established at the start of each project. This problem has been highlight by 
both groups but, while the testing facility personnel blame engineering management for creating these timing issues, engineering management blame the market requirements which are imposed on them from sales. This is a typical trait in any project with strict timing schedules, where people doing the work blame the person or the customer creating the pressure to deliver the assigned task on time. An additional suggestion from the testing facility personnel was to enhance the supply chain of spare parts during PD testing. Parts need to be on site at the appropriate time and having spares on hand would avoid having lengthy stoppages due to failures. Obviously, it would be impossible to have all the spares readily to hand, but a list of critical spares can be determined beforehand depending on risk in order to avoid such problems.

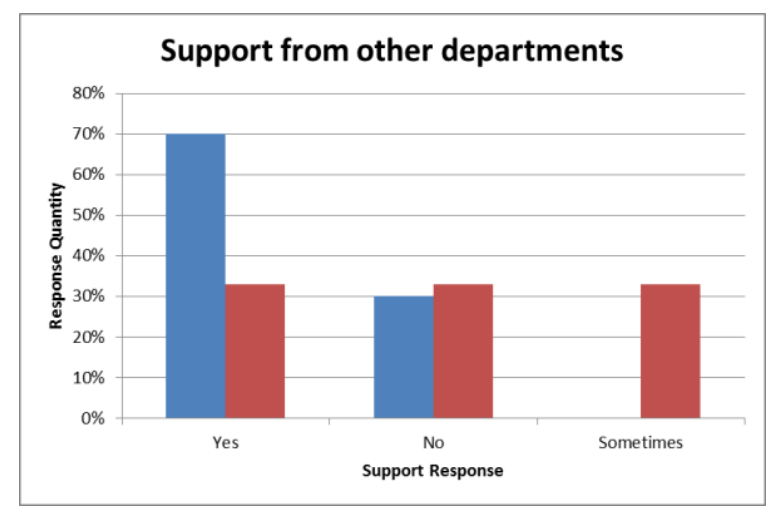

Figure 5. Support from other departments.

The questionnaire then explored the participant's perception of the support they got from other departments when problems arise. Responses received were mixed. Figure 5 shows a very positive response from the testing technicians, shown in blue, but these results are not accurate because when testing technicians encounter problems, they address them via their supervisor who is acting as a buffer. From the engineering group (shown in red) the response is evenly balanced between 'yes', 'no' and 'sometimes', which when quantified would result in a 50-50 response, a good indicator of an ineffective teamwork.

In terms of suggestions to improve current processes, the majority of testing technicians feel that better communication methods, better response time and timely action from project engineers are required. Engineering also indicated the need for better communication as the main driver to improve any of the current processes. They also pointed out that more team building exercises are required to improve team work to achieve project targets. Another interesting point identified was to 
introduce remote access to current testing and give the ability to engineers to review on-going work rather than wait for the final reports.

\subsection{Industrial Opinions on Issues Related to Data and Knowledge}

In this section of the questionnaire, an effort was made to quantify how much time is wasted looking for data and knowledge which is shown in Figure 6. From the responses, it is apparent that proper structures and simplification to search for data and knowledge are needed. More than $60 \%$ of responses felt that time is wasted looking for information that could have easily been found if it was filed in a structured way that could be easily searched and accessed. This issue can have significant repercussions because company data and knowledge is a very valuable company resource and if this knowledge is not reused the company may end up re-inventing the same thing over and over and having to pay for each iteration.

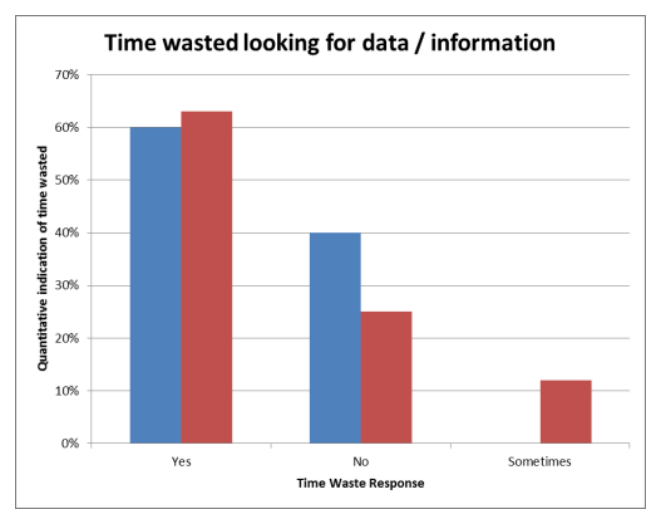

Figure 6. Time wasted looking for data / information

"Too much time trying to find information in the vast amount of systems / databases. Non-Value added activities when information should be readily available."

As an improvement, a consensus of developing better databases to get all the information required from one source was noted. Another important issue highlighted was the capturing and documenting of people's knowledge so that it can be shared; the company should be interested in investing further into this because once that specific employee leaves the company, all of his/her knowledge and information leaves with them, which will result in loosing that knowledge forever.

"Data \& Knowledge are not properly stored and it's not managed properly. Also test reports are not properly filled in and not securely stored." 
Testing technicians pointed out that they would find it beneficial if they could spend time following and observing other people's job functions and, in-turn, other people outside of the testing facility should spend time in the test cells to get a better understanding of what it takes to prepare and conduct tests. By having a broader view of the whole product life cycle, the different people involved could be more sensitive to the requirements of other job functions, which can result in improved teamwork.

"People should spend time in other departments to get a broader view of different job functions."

There is a general agreement that new tools and processes for knowledge capture need to be implemented onsite and globally within the company and this again created the motivation to develop the proposed framework shown in section 5.

"we need better storage \& sharing of knowledge to avoid repetition / future errors A transparent approach for all to share / communicate best practice etc"

In terms of keeping people better informed, several ideas emerged, such as project progress meetings, publishing live data via electronic boards or web portal/dashboard, a large Andon board inter alia.

\subsection{Main issues identified from the industrial investigation.}

The industrial investigation highlighted several communication and knowledge transfer issues and the following actions should be taken:

- Improve communication and documentation management in order to avoid costly mistakes when engineers can refer to the documentation to clarify any misunderstandings;

- Improve sharing of information between project stakeholders so that everyone is in the information loop;

- Improve the capture and documenting of employee knowledge, including tacit knowledge;

- Digitize and automate utilization metrics so that a facility's capacity is published for all to see;

- Publish live information of facility status in order to keep people informed of AS-IS situation;

- Increase face-to-face communication time in order to add an extra dimension to verbal communication - body language and facial expressions increases the confidence in what is being discussed; and

- Improve teamwork and remove departmental boundaries. 
New knowledge and personal know-how not stored within the mind-sets of other employees will be accessible. Most knowledge is stored for personal information management, to ensure their own departmental operation, but not always adding value to the organisation as a whole; this is a normal human trait found throughout human history whereby people keep their knowledge to themselves as a way of empowerment and securing their position within a social group, in this case a company. In today's global business environment, this know-how and personal knowledge, which has been developed through years of service within a firm, is the companies' intellectual property and must be shared more effectively with others. If a company wants to remain competitive, it is essential that it taps into this readily available resource, otherwise it will fail to keep up with its competition.

\section{The Proposed Product Development Testing Portal}

The aim of this industrial investigation, was to highlight and address real industrial issues faced by a PD testing facility and its main stakeholders. In order to address these issues proposed solutions/objectives need to be acknowledged in order to improve the efficiency of the utilization of PD test and validation facilities.

- Development of a Design Verification Plan and Report (DVP\&R) framework to improve documentation control and document security, giving better access and traceability;

- Development of an archive for testing reports which gives users access to information on previous tests performed on subassemblies which make up the final product;

- Development of a communication framework which will help keep all the relative people involved in a project informed with the latest information; the framework will provide a historical record of all communications throughout the project lifetime;

- Further development of an automated metrics system in order to simplify monitoring and monthly reports. The system should be able to feed information to web-based dashboards or electronic boards to inform people of what is going on during testing operations and provide a database of testing and rigging times to be used for future project planning; and

- Development of a knowledge capture and sharing framework in order to improve staff understanding of the testing processes and further improve personal development of employees.

The framework shown below in Figure 7, amalgamates the above objectives into a single framework to bridge the issues and shortcomings 
uncovered by the industrial investigation. The framework would enable knowledge re-use and avoid costly mistakes attributed to miscommunication or from reinventing the wheel, simply because inhouse knowledge has not been appropriately captured or shared within the organization. The improvements in testing information management would reduce, both amounts of tests being performed and the planned testing durations. Reductions in the amount of product testing would come from improved understanding of previous tests based on a sub-assemblies and component level. Because this information is not available nor accessible to the engineer, testing specifications test the final product as if no testing has been performed on the different sub-assemblies and components. Improved planning and facilities utilization would result from improved testing metric, which would highlight facilities issues and bottlenecks. Improved communications not only improve the testing execution amongst the testing engineers but also highlight design issues that can be implemented into new product design, improving future products.

The key areas identified in the industrial investigation will be incorporated into a tool that will bridge these shortcomings, resulting not only in improved PD test cycles, but also a reduction in the time to market. The idea behind this tool is to have one centralized area where all of the PD team requirements can be located and accessed by all engineers. The flow chart in Figure 7 offers a holistic idea of a communication, knowledge capture and sharing framework which can be developed as a tool to aid engineers and their collaborating partners in their day-to-day work, by having a single portal with a single version of the truth that caters for all PD testing needs. 


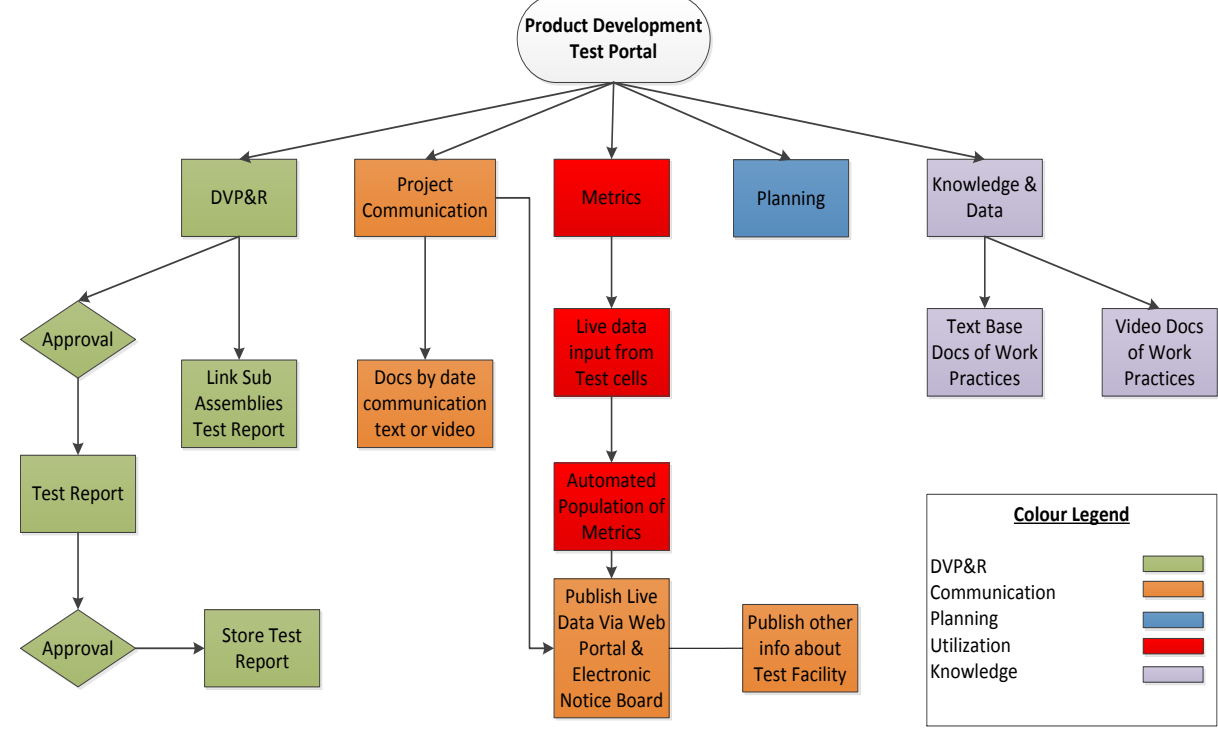

Figure 7. The Proposed Framework - Product Development Testing Portal

\section{$5 \quad$ Conclusions and Further Work}

Product design and manufacturing companies today acknowledge the important role communication and knowledge sharing have in order to gain a competitive advantage over their competitors. However, this can only be achieved if a company identifies its communication and knowledge needs and tackles them seriously, by capturing and re-using its in-house knowledge. The proposed framework is tailored to the collaborating company, but this does not rule out its use in other organisations. These finding can also be applied to other design or manufacturing companies and general business. These finding have been share at industrial workshops with companies from varying industries within the Kent, UK, region and the feedback and interest from these companies was positive, while also highlighting the same deficiencies identified in this study.

The next phase in this project is to finalise end-user requirements and create the required work flows to compliment the framework. This will be followed by an in-depth analysis to identify the tools that can be developed to satisfy these requirements. From this, a validation study of the developed tool will be carried out through the use of a case study that will examine the effectiveness and feasibility of the framework. 


\section{References}

Afonso, P., Nunes, M., Paisana, A. and Braga, A. (2008). 'The influence of timeto-market and target costing in the new product development success'. International Journal of Production Economics, 115, 559-568.

Akdevelioglu, M. (2015). 'The Influence of Intuitive Style on the Effect of Conflict on NPD Team Performance'.

Alavi, M. and Leidner, D. E. (2001). 'Review: Knowledge management and knowledge management systems: Conceptual foundations and research issues'. MIS Quarterly: Management Information Systems, 25, 107-136.

Argyle, M. (1969). 'Social interaction', London: Methuen, Transaction Publishers.

Becker, M. C. and Zirpoli, F. (2003). 'Organizing new product development: Knowledge hollowing-out and knowledge integration - The FIAT Auto case'. International Journal of Operations and Production Management, 23, 1033-1061.

Bhatt, G. D. (2001). 'Knowledge management in organizations: Examining the interaction between technologies, techniques, and people'. Journal of Knowledge Management, 5, 68-75.

Bryman, A. (2006). 'Integrating quantitative and qualitative research: how is it done?'. Qualitative research, 6, 97-113.

Cooper, R., Edgett, S. and Kleinschmidt, E. (2001). 'Portfolio management for new product development: Results of an industry practices study'. $R$ and D Management, 31, 361-380.

Crawford, E. R. and Lepine, J. A. (2013). 'A configural theory of team processes: Accounting for the structure of taskwork and teamwork'. Academy of Management Review, 38, 32-48.

Cummings, J. N. (2004). 'Work groups, structural diversity, and knowledge sharing in a global organization'. Management science, 50, 352-364.

Dahan, E. and Mendelson, H. (2001). 'An extreme-value model of concept testing'. Management science, 47, 102-116.

Daim, T. U., Ha, A., Reutiman, S., Hughes, B., Pathak, U., Bynum, W. and Bhatla, A. (2012). 'Exploring the communication breakdown in global virtual teams'. International Journal of Project Management, 30, 199212.

Davenport, T. H. and Prusak, L. (2000). 'Working Knowledge: How Organizations Manage what They Know', Harvard Business School Press.

Farh, C. I., Seo, M.-G. and Tesluk, P. E. (2012). 'Emotional intelligence, teamwork effectiveness, and job performance: the moderating role of job context'. Journal of Applied Psychology, 97, 890.

Fuchs, C., Hofkirchner, W., Schafranek, M., Raffl, C., Sandoval, M. and Bichler, R. (2010). 'Theoretical foundations of the web: cognition, communication, and co-operation. Towards an understanding of Web 1.0, 2.0, 3.0'. Future Internet, 2, 41-59. 
Gentry, W. A. and Kuhnert, K. W. (2007). 'Sending signals: Nonverbal communication can speak volumes'. Leadership in Action, 27, 3-7.

Griffin, A. (1997). 'Modeling and measuring product development cycle time across industries'. Journal of Engineering and Technology Management, $14,1-24$.

Hislop, D. (2002). 'Mission impossible? Communicating and sharing knolwedge via information technology'. Journal of Information Technology, 17, 165 $-177$.

Hoegl, M. (2005). 'Smaller teams-better teamwork: How to keep project teams small'. Business Horizons, 48, 209-214.

Jones, G. R. and George, J. M. (1998). 'The experience and evolution of trust: Implications for cooperation and teamwork'. Academy of management review, 23, 531-546.

Jürgens, U. (2013). 'New product development and production networks: global industrial experience', Springer Science \& Business Media.

Kahn, K. B. (2012). 'The PDMA Handbook of New Product Development', Wiley.

Lu, Y., Loh, H. T., Brombacher, A. C. and Ouden, E. d. (2000). 'Accelerated stress testing in a time-driven product development process'. International Journal of Production Economics, 67, 17-26.

Maravelias, C. T. and Grossmann, I. E. (2004). 'Optimal resource investment and scheduling of tests for new product development'. Computers \& Chemical Engineering, 28, 1021-1038.

Mercer, D. K. and Myers, S. (2013). 'Teamwork is the ability to work together toward a common vision. The ability to direct individual accomplishments toward organizational objectives. It is the fuel that allows common people to attain uncommon results.-Andrew Carnegie'. Academy Model, 2.

Miller, P. (1998). 'Mobilising the Power of What you know: Handbook of Knowledge Management', London, Random House.

Minderhoud, S. and Fraser, P. (2005). 'Shifting paradigms of product development in fast and dynamic markets'. Reliability Engineering \& System Safety, 88, 127-135.

Mohannak, K. (2013). 'Organisational knowledge integration towards a conceptual framework'. Salamanca.

Nair, R., Tambe, M. and Marsella, S. (2005). 'The role of emotions in multiagent teamwork'. Who Needs Emotions, 311-329.

Nonaka, I. and Takeuchi, H. (1995). 'The Knowledge-creating company', Oxford, UK, OxFord University Press.

Phipps, R. (2012). 'Body Language: It's What You Don't Say That Matters', Wiley.

Salas, E., Cooke, N. J. and Rosen, M. A. (2008). 'On teams, teamwork, and team performance: Discoveries and developments'. Human Factors, 50, 540547. 
Woodcock, B. 2014. TEAMWORKING SKILLS [Online]. www.Kent.ac.uk. Available: http://www.kent.ac.uk/careers/sk/teamwork.htm [Accessed 18/10/2014 2014].

Yang, J. T. (2004). 'Job-related knowledge sharing: comparative case studies'. Journal of Knowledge Management, 8, 118-126. 